\title{
Everywhere is Nowhere: A Systematic Review of Menstrual Health and Hygiene Management (MHHM) as a Human Right
}

Suruchi Sood ( $\square$ ss3724@drexel.edu )

Sarah Stevens

Drexel University School of Public Health

Maho Okumura

Drexel University School of Public Health

Astha Ramaiya

Drexel University School of Public Health

Michael Hauer

Drexel University School of Public Health

\section{Research article}

Keywords: Menstrual health and hygiene management, menstrual hygiene management, adolescent girls, human rights

Posted Date: January 3rd, 2020

DOI: https://doi.org/10.21203/rs.2.19997/v1

License: (1) This work is licensed under a Creative Commons Attribution 4.0 International License. Read Full License 


\section{Abstract}

Background: In many countries, stigma surrounds menstruation, which impacts several Sustainable Development Goals, including good health, quality education, gender equality, and water and sanitation. Despite its relationship with several development issues, menstrual health and hygiene management among adolescents has until recently been ignored by practitioners and researchers. This paper is a systematic review of existing literature and argues that menstrual health and hygiene management is a human rights issue, cross-cutting through development domains of health, education, nutrition, child protection, and water, sanitation, and hygiene.

Methods: Four coders independently screened PubMed, Academic OneFile, and Google Scholar to obtain articles using iterations of the key terms: menstrual health; adolescents; health outcomes; education; nutrition; water, sanitation, and hygiene; and child protection. English language primary studies in peerreviewed or grey literature articles published after 2000, that mentioned adolescents, health or hygiene, and menstruation or menstrual were included. A 9-item scale was used to rate selected full-text articles as strong, moderate, or weak. Synthesis of the results were narrative and examined the relationships between menstrual health and hygiene management and the cross-cutting domains.

Results: In total, 28,745 articles were screened, with 84 articles included in the full-text review and quality assessment. Nine articles were coded as "strong" (10.8\%), 46 (55.4\%) as "moderate," and $28(33.7 \%)$ as "weak." More than $60 \%$ of the articles examined the relationship between menstrual health and hygiene management and health (37.3\%) or water, sanitation, and hygiene (25.3\%). Only 11 manuscripts examined menstrual health and hygiene management as a cross-cutting issue impacting more than one development domain.

Conclusions: Access to adequate facilities and menstrual health and hygiene management resources are the most common relationships documented within literature. However, there is little focus on menstrual health and hygiene management in the context of other development domains, highlighting the fact that poor menstrual health and hygiene management has not been studied as a human rights issue, negatively impacting millions of girls. Using a cross-cutting, human rights framework to address inadequate menstrual health and hygiene management is fundamental to promoting menstrual health and hygiene management with dignity among girls and women across the globe.

\section{Background}

\section{Introduction}

Menstruation is a natural, monthly occurrence for women and girls of reproductive age. Beginning sometime in adolescence, menarche-the initiation of menstruation-is an important phase for an adolescent girl, signaling her transition into puberty and womanhood (1). After reaching menarche, there is a need to ensure adequate menstrual health and hygiene management (MHHM) for adolescent girls and women, so that they can fully participate in daily activities. Adequate MHHM is defined as the "use of 
clean menstrual management material to absorb or collect blood that can be changed in privacy as often as necessary for the duration of the menstruation period, using soap and water for washing the body as required and having access to facilities to dispose of used menstrual management materials" $(2,3)$.

Despite being a normal, biological process, many adolescent girls and women are unable to practice adequate MHHM. Literature across low- and middle-income countries demonstrates that approximately $50 \%$ of girls and women practice inadequate MHHM because of reasons beyond their control, such as social restrictions, lack of knowledge about menstruation, and lack of menstrual hygiene products and facilities $(4,5)$. Adolescent girls and women not being able to adequately practice MHHM have farreaching negative impacts on their lives, such as mobility restrictions, restrictions on attendance at school and community gatherings, compromised safety, and additional stress and anxiety (6). When their basic MHHM needs go unmet, adolescent girls and women are denied their rights to manage their menstrual cycle in a dignified, healthy way (6).

As MHHM encompasses a significant portion of adolescent girls' and women's daily lives, inadequate MHHM negatively impacts their health, education, nutrition, safety, and hygiene, making MHHM a human rights issue (5, 7-10). Inadequate MHHM has implications for several Sustainable Development Goals (SDGs), including SDG 3: good health; SDG 4: quality education; SDG 5: gender equality; and SDG 6: water and sanitation (7). Figure 1 outlines how MHHM is a cross-cutting public health and human rights challenge that requires attention and action if SDGs 3-6 are to be attained $(7,11)$.

\section{[INSERT FIGURE 1]}

\section{Background of Current Literature}

The connections between MHHM and the individual development domains of water, sanitation, and hygiene (WASH); health; education; nutrition; and child protection are documented in the literature. With regards to education, the relationship with $\mathrm{MHHM}$ is centered around schools providing adequate health education programs. MHHM also arises as an education issue when menstruation impacts girls' school attendance, thus impacting the completeness and quality of their education $(4,12)$.

WASH plays a significant role in MHHM as suitable WASH facilities are necessary for the attainment of adequate MHHM. A lack of appropriate WASH facilities at school can impact school attendance, and inadequate WASH facilities at home can reduce overall quality of life $(13,14)$. According to UNICEF $(6)$, over 335 million girls still go to schools without clean water and soap, making it crucial to have private and adequate WASH facilities to practice proper MHHM.

The relationship between MHHM and health is mostly measured by access to healthcare or seeking healthcare, and the health effects of menstruation, such as irregular cycles and dysmenorrhea, and infections. Several studies show that being able to access healthcare and MHHM resources, such as disposable absorbents positively correlate with fewer symptoms of menstruation; therefore, adolescent girls not having adequate access to such resources impact their daily lives, tying into the notion of health as a human rights issues $(9,15,16)$. 
Menstruation has also been related to dietary restrictions, which impacts the nutrition of girls. Scientific studies show that the number of adolescent girls facing restrictions on eating specific foods range from $4.6 \%$ to $70 \%$ worldwide (17-29). As women and girls are already discriminated against in comparison to men and boys in terms of food provision, there is a compounding effect that makes them more vulnerable to under-nutrition. Under-nutrition reduces the capabilities of adolescent girls and has long-term implications for the physiologic function of the body and the ability to thrive later in life $(21,30)$.

Finally, the relationship between MHHM and child protection has been depicted mostly through addressing child marriage. Studies have shown a significant association between age at menarche and child marriage (31-33). When an adolescent girl attains menarche, she is thought to be a woman, signaling maturity and her ability to bear a child $(34,35)$. Family honor and social traditions dictate that an adolescent girl who has attained menarche is of marriageable age $(5,10,32,35)$. Child marriage is a harmful practice because it is associated with significantly higher rates of mental and physical health conditions, such as maternal mortality and morbidity, infant mortality and morbidity, intimate partner violence, depression, and anxiety.

While there is ample literature documenting the relationships between MHHM and the individual development domains of WASH; health; education; nutrition; and child protection, the literature is fragmented, stems from different academic disciplines, and frames MHHM as an issue within each of the five domains. This systematic review argues that MHHM has been hitherto neglected in the overall development sphere and aims to evaluate the extent to which adequate MHHM among adolescent girls is a fundamental human right. Jyoti Sanghera stated that, "Stigma around menstruation and menstrual hygiene is a violation of several human rights, most importantly of the right to human dignity" (36). In addition to this violation of human dignity, stigma around MHHM perpetuates violations of rights to education, health, consensual marriage, and WASH (37). The Universal Declaration of Human Rights (UDHR) is a landmark document for human rights, which holds all participating nations accountable to its tenets (38). According to the UDHR, people are the 'rights holders' to security, dignity, and well-being and states are the 'duty-bearers' to respect, protect, and fulfil those rights (39). Table 1 outlines the covenants, comments, and articles that are most relevant to MHHM and how the states are violating their rights as duty-bearers.

Table 1: Human Rights Articles and how the Rights are Respected, Protected, and Fulfilled? 


\section{Right to human dignity and non-discrimination}

Universal Declaration of Human

Rights (UN General Assembly, 1948)
(1): "All human beings are born free and equal in dignity and rights."
States do not protect AG right to dignity

(2): "Everyone is entitled to all the rights and freedoms set forth in this Declaration, without distinction of any kind, such as sex"

\section{Right to education}

Convention on the Rights of the Child (The United Nations, 1990)
States do not fulfil AG right to freedom and nondiscrimination. (28e): "States Parties recognize the right of the child to education, and with a view to achieving this right progressively and on the basis of equal opportunity: Take measures to encourage regular attendance at schools and the reduction of drop-out rates."

\section{Right to consensual marriage}

Convention on the Elimination of All

Forms of Discrimination against Women (UN General Assembly, 1981)
(16.1): "States Parties shall take all appropriate measures to eliminate discrimination against women in all matters relating to marriage"
States do not fulfil to take measures to encourage regular attendance at schools. Which impacts health and future capabilities.

\section{Highest attainable standard of health and comprehensive health education}

International Covenant on Economic, Social and Cultural Rights

(UN General Assembly, 1966)

International Covenant on Economic, Social and Cultural Rights - General Comment 14 (UN Economic and Social Council (CESCR), 2000)

\begin{abstract}
(12.1): "The States Parties to the present Covenant recognize the right of everyone to the enjoyment of the highest attainable standard of physical and mental health." (34): "should refrain from limiting access to...health-related information, including sexual education and information, as well as from preventing people's participation in health-related matters."

(44d): "provide education and access to information concerning the main health problems in the community, including methods of preventing and controlling them".
\end{abstract}

States do not protect the girl from getting married before legal age, which impacts education and health.

\section{Right to water and sanitation}

International Covenant on Economic,

Social and Cultural Rights General

Comment 15

(UN Economic and Social Council

(CESCR), 2003)
(2): "The human right to water entitles everyone to sufficient, safe, acceptable, physically accessible and affordable water for personal and domestic uses."
States do not fulfil the right to physical and mental health.

States do not fulfil the right to comprehensive health education.
States do not fulfil the right to adequate facilities and clean water. 
Identifying MHHM as a health and human rights issue requires states to respect, protect, and fulfil the right of its citizens to adequate MHHM (39). Placing the UDHR as its foundation and using the human rights framework, this manuscript aims to assess existing literature to evaluate the practice of treating MHHM as a cross-cutting human rights issue through a narrative systematic review.

\section{Methods}

\section{Eligibility Criteria}

To be included in the review, articles had to: be in English language (this was the only language all coders understood); mention adolescents, health or hygiene, and menstruation or menstrual; be primary studies in peer-reviewed or grey literature; and be published after year 2000 (considered adequate to gain a full sense of the extant literature). The exclusion criteria were: not in English language; did not have the key terms adolescents, health or hygiene, or menstruation or menstrual; systematic review, meta-analysis, commentaries, dissertations or editorials or not peer-reviewed; or published before 2000 .

\section{Information Sources}

A total of four coders independently screened PubMed, Academic OneFile, and Google Scholar to obtain articles. Each coder focused on the relationship of MHHM with either health outcomes, education, child protection, nutrition, or WASH. If the article was not available in the locally or through the interlibrary loan, the corresponding author was contacted through email by the coder. Furthermore, the bibliographies of all included articles were screened to identify additional relevant articles pertaining to the research question.

\section{Search}

Iterations of seven key terms were used in the search: i) menstrual health; ii) adolescents; iii) health outcomes; iv) education; v) nutrition; vi) WASH; and vii) child protection. Table 2 includes the key terms and the iterations used across all three databases, taking into account the eligibility criteria identified above.

Table 2: Seven key term combinations used to conduct searches in PubMed, Academic OneFile and Google Scholar 


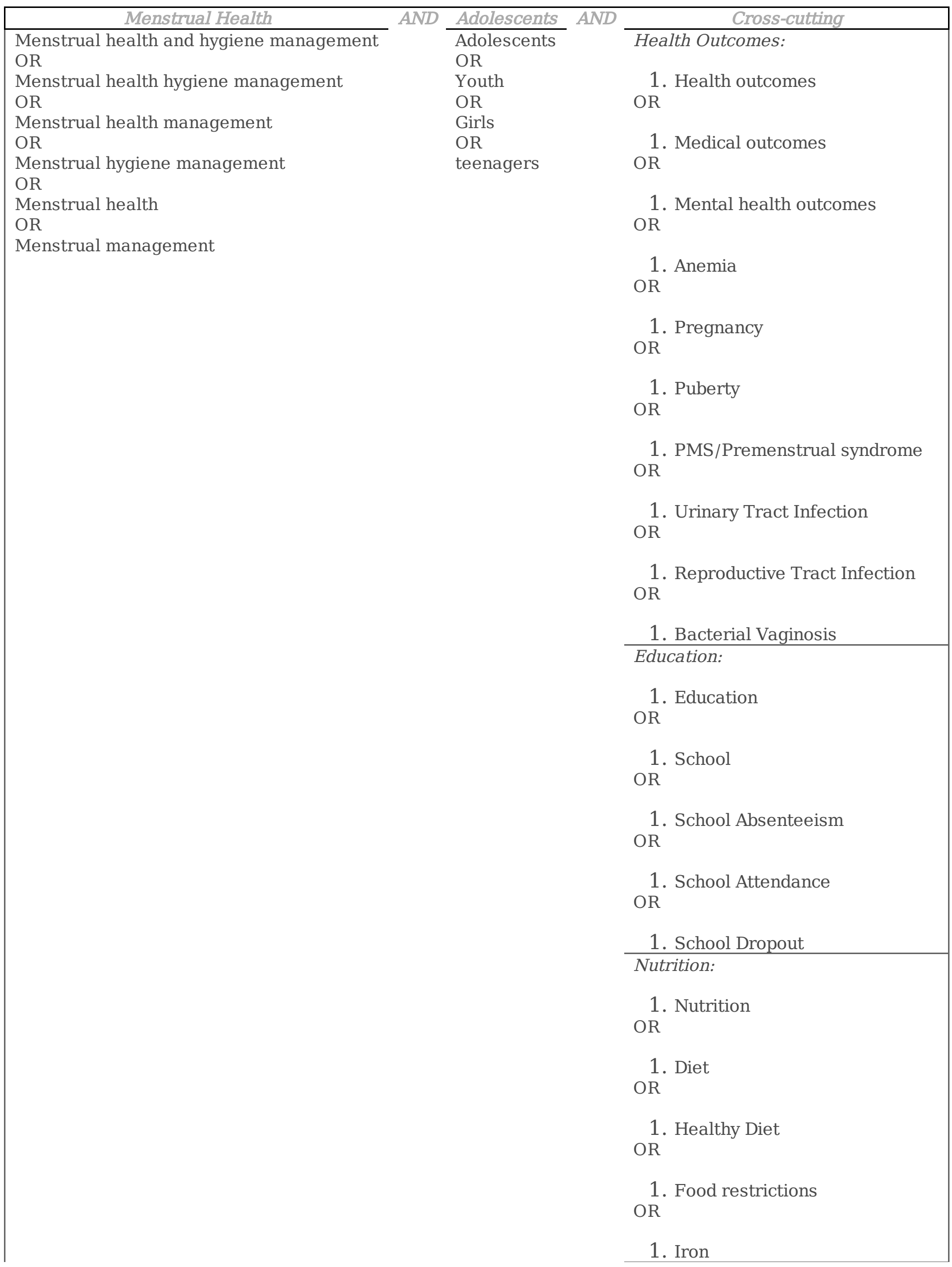




\begin{tabular}{|c|}
\hline WASH: \\
\hline $\begin{array}{l}\text { 1. WASH } \\
\text { OR }\end{array}$ \\
\hline $\begin{array}{l}\text { 1. Water } \\
\text { OR }\end{array}$ \\
\hline $\begin{array}{l}\text { 1. Sanitation } \\
\text { OR }\end{array}$ \\
\hline $\begin{array}{l}\text { 1. Personal Hygiene } \\
\text { OR }\end{array}$ \\
\hline $\begin{array}{l}\text { 1. WASH AND privacy } \\
\text { OR }\end{array}$ \\
\hline $\begin{array}{l}\text { 1. Toilet } \\
\text { OR }\end{array}$ \\
\hline $\begin{array}{l}\text { 1. Latrine } \\
\text { OR }\end{array}$ \\
\hline $\begin{array}{l}\text { 1. Handwashing } \\
\text { OR }\end{array}$ \\
\hline $\begin{array}{l}\text { 1. Bathing } \\
\text { OR }\end{array}$ \\
\hline 1. Cloth \\
\hline Child Protection: \\
\hline $\begin{array}{l}\text { 1. Child protection } \\
\text { OR }\end{array}$ \\
\hline $\begin{array}{l}\text { 1. Child rights } \\
\text { OR }\end{array}$ \\
\hline $\begin{array}{l}\text { 1. Child Marriage } \\
\text { OR }\end{array}$ \\
\hline $\begin{array}{l}\text { 1. FGM } \\
\text { OR }\end{array}$ \\
\hline $\begin{array}{l}\text { 1. FGMC } \\
\text { OR }\end{array}$ \\
\hline $\begin{array}{l}\text { 1. Abuse } \\
\text { OR }\end{array}$ \\
\hline $\begin{array}{l}\text { 1. Exploitation } \\
\text { OR }\end{array}$ \\
\hline $\begin{array}{l}\text { 1. Trafficking } \\
\text { OR }\end{array}$ \\
\hline $\begin{array}{l}\text { 1. Commercial sexual exploitation } \\
\text { OR }\end{array}$ \\
\hline $\begin{array}{l}\text { 1. Child Labor } \\
\text { OR }\end{array}$ \\
\hline
\end{tabular}




\section{Study Selection}

The PRISMA flow diagram used to screen for articles that answered the research question and met the eligibility criteria. Screening was done at the title, abstract, and full-text review stages. When full-text articles were excluded, a reason was reported. Due to the high volume of results in Google Scholar $(n=26,004)$, article selection was based on relevance, i.e. if twenty articles in a row were not relevant to the topic, the research moved on to the next search. Figure 2 outlines the PRISMA diagram of the systematic review process.

[INSERT FIGURE 2]

\section{Data Collection Process}

Each coder assessed the quality of the selected full-text articles. Sirriyeh, Lawton, and Garner's (40) coding matrix and quality assessment was adapted for this study, as it allowed assessment of quantitative, qualitative, and mixed-method studies and demonstrated good face validity and reliability. Table 3 outlines the criteria used for coding and assessment.

Table 3: Criterion to assess quality of manuscripts 


\begin{tabular}{|c|c|c|}
\hline Item & Coding Category & Description \\
\hline 1. & Citation & Full citation APA style \\
\hline 1. & Type of manuscript & $\begin{array}{l}\text { Peer Review Journal Article, Editorials/Commentary, Report, Newspaper } \\
\text { Article }\end{array}$ \\
\hline 1. & Type of sub-publication & Original article, narrative systematic review, meta-analysis \\
\hline 1. & Precise location & School, village, district, province, state, country \\
\hline 1. & Location & Enter country where study was conducted \\
\hline 1. & Location: Region & Enter the region of the world \\
\hline 1. & Intervention & $\begin{array}{l}\text { Did the manuscript mention/describe an intervention? If yes, describe the } \\
\text { intervention. Make sure to state who the intervention was for, the } \\
\text { intervention activities, the dose, the site where activities took place, and } \\
\text { duration of the intervention. }\end{array}$ \\
\hline 1. & Audience: Primary & What was the primary audience of the intervention? \\
\hline 1. & Audience: Secondary & What was the secondary audience of the intervention? \\
\hline 1. & $\begin{array}{l}\text { Level of influence: } \\
\text { intrapersonal }\end{array}$ & $\begin{array}{l}\text { Was the intervention addressing the intrapersonal domain of the socio- } \\
\text { ecological model? }\end{array}$ \\
\hline 1. & $\begin{array}{l}\text { Level of influence: } \\
\text { interpersonal }\end{array}$ & $\begin{array}{l}\text { Was the intervention addressing the interpersonal domain of the socio- } \\
\text { ecological model? }\end{array}$ \\
\hline 1. & $\begin{array}{l}\text { Level of influence: } \\
\text { social }\end{array}$ & $\begin{array}{l}\text { Was the intervention addressing the social domain of the socio-ecological } \\
\text { model? }\end{array}$ \\
\hline 1. & $\begin{array}{l}\text { Level of influence: } \\
\text { policy }\end{array}$ & $\begin{array}{l}\text { Was the intervention addressing the policy domain of the socio-ecological } \\
\text { model? }\end{array}$ \\
\hline 1. & MHHM Definition & $\begin{array}{l}\text { Was a definition for menstrual health and hygiene management stated? If yes, } \\
\text { enter the definition. }\end{array}$ \\
\hline 1. & Evaluation & If an intervention was described, was an evaluation conducted? \\
\hline 1. & MHHM Variable & $\begin{array}{l}\text { Is the MHHM variable the independent, dependent or } \\
\text { confounding/mediator/moderator variable? }\end{array}$ \\
\hline 1. & Other study variables & $\begin{array}{l}\text { What are the other study variables? Are these the independent, dependent or } \\
\text { confounding variables? }\end{array}$ \\
\hline 1. & Type of study & $\begin{array}{l}\text { Cross-sectional, Randomized control trial, quasi-experimental, case-control, } \\
\text { longitudinal }\end{array}$ \\
\hline 1. & Methods & $\begin{array}{l}\text { What type of methods were described in the manuscript? Qualitative, } \\
\text { Quantitative, Mixed-Methods, Participatory }\end{array}$ \\
\hline 1. & Key Results & Discussion of key results (if quantitative study, state the significant findings) \\
\hline 1. & $\begin{array}{l}\text { Conceptual/Theoretical } \\
\text { Frameworks }\end{array}$ & Theory of change is outlined and applied to examine the key components \\
\hline 1. & $\begin{array}{l}\text { Statement of } \\
\text { aims/objectives } \\
\text { (Research question) }\end{array}$ & $\begin{array}{l}\text { Description on why the manuscript was written and its contribution to } \\
\text { literature is provided. }\end{array}$ \\
\hline 1. & $\begin{array}{l}\text { Justification for } \\
\text { analytical method } \\
\text { selected }\end{array}$ & Detailed explanation on why an analytical method was selected. \\
\hline 1. & Sample Description & Who are the participants of the study? Include the sample size as: $(\mathrm{n}=)$ \\
\hline 1. & $\begin{array}{l}\text { Sample size } \\
\text { consideration in the } \\
\text { analysis }\end{array}$ & $\begin{array}{l}\text { How was the sample size calculated? For quantitative studies, power analysis } \\
\text { is provided; for qualitative studies enough individuals to reach saturation. }\end{array}$ \\
\hline & ment & iable? (e.g. was pretesting conducted? Was a literature \\
\hline
\end{tabular}




\begin{tabular}{|cll|}
1. & of reliability & $\begin{array}{l}\text { review conducted on the measures used? Was reliability analysed?). Enter } \\
\text { text to explain. }\end{array}$ \\
\hline 1. & Strengths & $\begin{array}{l}\text { Discussion of strengths of all aspects of study design, data collection, or } \\
\text { evaluation as stated by the authors of the manuscript }\end{array}$ \\
\hline 1. & Limitations & $\begin{array}{l}\text { Discussion of limitations of all aspects of study design, data collection, or } \\
\text { evaluation as stated by the authors of the manuscript }\end{array}$ \\
\hline 1. & Recommendations & $\begin{array}{l}\text { Discussion on specific recommendations for improvement of measure as } \\
\text { stated by the authors of the manuscript }\end{array}$ \\
\hline 1. & Assessment of Quality* & $\begin{array}{l}\text { Each manuscript will be given a rank of strong, moderate and weak based on } \\
\text { specific criteria (item 21 - 29) outlined above. }\end{array}$ \\
\hline
\end{tabular}

*: Assessed on a scale of 0 - 3 based on items $21-29$

The assessment criteria were a 9-item scale (items 21 - 29). A number was assigned for each criterion. If the outlined criterion was not mentioned, 0 was given. If there was limited mention of the criterion, 1 was given. Some discussion of the criterion received a 2 and if there was thorough discussion of everything outlined in the criterion, 3 was given. A maximum of 27 points could be given to each study. If a study received $19-27$ points, it was coded as a "strong," if a study received $10-18$ points, it was coded as "moderate," and if a study received 0 - 9 points, it was coded as "weak."

To ensure reliability of the quality assessment scores, double coding was conducted on a sub-sample of the articles. A fifth coder independently coded $20 \%$ of the database to ensure inter-rater reliability. Approximately $70 \%$ of the scores were within 4 points of the original score. Differences in coding were discussed and challenges were resolved.

\section{Results}

Overall, a total of 28,745 articles were screened across the three databases, with 3,427 included as part of the abstract review (11.9\%), 371 for full-text eligibility (1.3\%), and 84 in the desk review $(0.3 \%)$.

Based on the quality assessment for the 84 articles, nine articles were coded as "strong" (10.8\%), 46 (55.4\%) were coded as "moderate," and 28 (33.7\%) were coded as "weak." The two criteria that had the highest percentages of 0's were "outlining a conceptual framework" (73.96\%) and "justification for analytical method" (60.42\%). The two criteria that had the highest number of 3's were "outlining a research question" (64.58\%) and "recommendations" (43.75\%). Table 4 includes background information on the 84 articles where over $80 \%$ reported cross-sectional data and more than half (54.2\%) used quantitative methodologies. The studies were derived from multiple geographical locations. Almost all studies involved adolescent girls. 
Table 4: Summary of Articles Included in the Systematic Review ( $N=84)$

\begin{tabular}{lll} 
Categories & N & $\%$ \\
\hline Methodology & & \\
\hline Quantitative & 46 & 54.2 \\
\hline Qualitative & 17 & 20.5 \\
\hline Mixed-methods & 12 & 14.4 \\
\hline Participatory & 9 & 10.8 \\
\hline Cross-sectional & 69 & 82 \\
\hline Geographic Regions & & \\
\hline South Asia & 35 & 42.2 \\
\hline Eastern Africa & 35 & 42.2 \\
\hline Southern Africa & 24 & 28.9 \\
\hline West and Central Africa & 9 & 10.8 \\
\hline Middle East and North Africa & 9 & 10.8 \\
\hline East Asia and the Pacific & 4 & 4.8 \\
\hline Americas and the Caribbean & 1 & 1.2 \\
\hline Combination & 1 & 1.2 \\
\hline Targeted Audience & 63 & 7.2 \\
\hline Girls & 16 & 19.3 \\
\hline School staff and administrators & 3 & 3.6 \\
\hline Community members & & \\
\hline Boys & 63 \\
\hline Parents of girls & & \\
\hline Non-governmental organizations and ministries & & \\
\hline
\end{tabular}

More than $60 \%$ of the articles looked at the relationship of MHHM with health (37.3\%) or with WASH (25.3\%). The rest looked at the relationship of MHHM with education (13.3\%) nutrition (7.2\%), and child protection (2.4\%). Additionally, $14.4 \%$ of the studies examined the relationship between MHHM and two 
development issues, for example, $7.2 \%$ of the articles examined the links between adequate MHHM with WASH and education.

MHHM was defined in only seven (8.4\%) articles. None of the definitions matched WHO/JMP's (2012) definition, which summarizes the sub-constructs of procurement, storage, personal hygiene, privacy, frequency of changing and disposal. All seven definitions outlined personal hygiene, six included procurement of clean absorbent, four included privacy and discreet disposal, and two included frequency of changing the absorbent. None of the definitions specified storage of absorbents.

Only 19 articles referenced theories, with the most commonly used theory being the socioecological model, which represents a social system with every level of the system impacting the individual. Other mentioned theories include the grounded theory, social cognitive theory, the PRECEDE model, MRC framework, and feminist theory.

Access to adequate facilities emerged as a major factor, with ramifications for child protection, WASH, education, and health. A total of 30 articles (34\%) outlined the relationship between MHHM and access to facilities. Lack of facilities were also examined in the context of knowledge, restrictions, seeking healthcare, facilities available in school, access to information and support, and not disposing the menstrual absorbent in the toilet or latrine. Limited access to facilities was associated with dirty and constricted water and sanitation facilities within the school and home environment. The cycle of inadequate procurement of clean menstrual absorbents, infrequent changing of absorbents, inadequate drying of absorbents in the sun, and unsafe disposal further led to physical discomfort, inconvenience, embarrassment, and school absenteeism. Seven studies demonstrated that access to facilities (including covered toilets, locked doors, and availability of clean absorbents, water, soap, and dustbins) coupled with education programs was protective for MHHM and school attendance during menstruation (41-47).

Sociodemographic factors that came into play included poverty, social restrictions, secrecy around menstruation within the societies in which the studies took place, lower socio-economic status, and mothers with lower literacy. These factors were also associated with lack of facilities $(48,49)$.

14 articles outlined the relationship between MHHM with health and nutrition. Some manuscripts focusing on this also tangentially discussed MHHM in the context of educational achievement. One article demonstrated that those with better individual health had better menstrual health $(p=0.001)$ (50). Most of the studies associated poor MHHM with social secrecy and taboos surrounding menstruation, which led adolescent girls to use unhygienic methods (cloth), stay home from school, not exercise, and be unable to perform daily tasks during menstruation. This in turn led to adolescent girls being significantly more likely to exhibit at least one symptom of a reproductive tract infection $(R T I)(O R=1.046-1.94, p<0.05)$, vaginal discharge $(\mathrm{OR}=1.303, \mathrm{p}<0.001)$, urinary tract infection (UTI) (OR: 1.38, $\mathrm{p}<0.05)$, and sexually transmitted infections (STI), as well as lower likelihood of seeking treatment for any of these health problems $(15,51$ 56). One article provided contradictory information by showing no association between either washing the cloth with soap and water or not, or drying the cloth in the sun or not and having RTI/ STI symptoms (57). Two articles outlined a negative relationship between adequate MHHM and nutrition. Religion and 
mothers' education showed either societal-imposed or self-imposed restrictions, such as avoiding food during menstruation to manage menstrual flow $(48,58)$.

There were 15 articles (18\%) outlining the importance of pre-menarche training and health education that cut across health, education, and WASH issues. $(12,44,50,57,59-69)$. These programs covered all definitional aspects of MHHM, all of which were operationalized except for the ability to change the absorbent in privacy. Additional MHMM information in these programs included regularity of menstrual cycle, knowledge, health seeking behavior, student's behavior during first day of menstruation, tendency to stay at home, school absenteeism during menstruation, change in diet during menstruation (restrictions), and methods for managing menstrual problems.

Overall, there was a lack of consistency in the results when it came to pre-menarche training. Those who had prior knowledge on menstruation had better handwashing (69), had a higher proportion reporting no pain during menses $(29.3 \%$ vs $20.7 \%, p=0.05)$, had a higher proportion having no effect on schooling life (33.3\% vs $19.8 \%, p<0.01)$, had a higher proportion using sanitary pads $(75.1 \%$ vs $61.7 \%, p<0.01)$, and had a higher proportion disposing absorbents by burning (35.5\% vs $25.2 \%$, p<0.01) (59). At the same time, premenarche training and frequency of changing absorbent were not significantly associated (Aniebue et al., 2009). In one study, those who did not have prior knowledge on menstruation had better disposal practices (69).

Results from studies summarizing health education programs in schools showed that after adjusting for other co-factors, those who had never received health education had a $44 \%$ greater probability $(p=0.04)$ of dysmenorrhea than those who had previously received health education (62). Health educational programs had a positive correlation with improved intention to visit the health center at any time, increased knowledge, better attitudes, hygienic choice of absorbent, increased frequency of changing sanitary pads, reusing of cloth after washing, proper cleanliness of genitalia during menstruation, improved self-care behavior, increased bathing during menstruation, increased school attendance, fewer health complications, and seeking treatment for RTI or STI as compared to the control group $(12,44,50,57,60,61,64-68)$. One study demonstrated that, while training by either parents and health trainers was beneficial in comparison to no training, school health trainers elicited better MHHM behaviors (63).

\section{Discussion}

The systematic review found that most studies were set in developing, low- and middle-income countries with India having the highest representation, in 29 articles (35\%). This is in line with developing countries having a heavier burden on the lack of or limited water and sanitation services (70). As the results of some studies suggest, putting the focus on developing countries for improving MHHM is essential because cultural and traditional beliefs that are negative towards menstruation still exist, teachers do not have sufficient knowledge of MHHM, girls cannot afford to buy disposable sanitary pads, and there is a lack of adequate WASH facilities in schools (71). This in and of itself supports the idea that MHHM is a crosscutting issue and that future approaches to improve MHHM should take a multi-sectoral approach. 
This systematic review sought to understand the extent to which adequate MHHM is related to WASH, health, education, nutrition, and child protection. Overall, the quality of the studies was too variable to make explicit conclusions on MHHM as a human rights issue, with $89 \%$ being of low or moderate quality when evaluated by the adapted quality assessment scale. Nonetheless, the results do demonstrate relationships between MHHM and the SDG goals and provided important insight into future research and programming to consider MHHM holistically in the context of health, education, WASH, child protection, and nutrition. One of the most salient recommendations from the systematic review is the need to standardize the concept and definition of MHHM.

The review illustrated that most articles did not explicitly consider MHHM as a human rights issue, but rather framed it at as a single issue or in some cases a combination of two issues. Primarily, articles framed $\mathrm{MHHM}$ as either a health, wash, or education issue $(42 \%, 26 \%$, and $21 \%$ respectively), while only $7 \%$ focused on nutrition and $2 \%$ on child protection. The articles that focused on more than one topic area mostly combined WASH with education. For example, a result found in multiple studies was that menstruation has a negative impact on education because girls miss school due to schools lacking adequate and private WASH facilities; this in turn leads to gender discrimination in the school environment (72). The other common combination of topics was health and education, with studies that showed lack of proper health education due to secrecy and taboos surrounding menstruation led to girls using unhygienic methods during menstruation and thus, increased risks of vaginal discharge, urinary tract infections, and sexually transmitted infections.

Only a handful of studies utilized a multi-disciplinary approaches to address MHHM, which calls for increasing the integration of less represented sectors, such as nutrition and child protection, in future research and programs.

Using theories and conceptual models is imperative for evidence-based research, because they provide a roadmap of how to achieve the desired behavior change. These frameworks then serve as a guide to design and evaluate interventions and programs. However, only 19 articles $(23 \%)$ included in this study mentioned using a conceptual model or theory. The low percentage of studies employing a theory or model as a basis for the research demonstrates the need to emphasize this approach. Regardless of the theory chosen, future studies should be created using a framework to assure measurability of their efficacy. Studies using this model often take a multi-level approach to attain the maximum level of impact. The socioecological model takes into account societal and cultural norms, environmental and social influences, and personal perceptions and is frequently used to create effective MHHM interventions (45).

While most of the studies targeted adolescent girls, some studies also targeted women, parents, schoolteachers, male students, and school administrators. Targeting not just girls but other influential members of the society allowed studies to use a participatory approach to gain a better understanding of different perspectives of girls' challenges and experiences, as well as the gaps in knowledge and resources regarding MHHM in the target communities. One study by Long (73) conducted focus group discussions with mothers, teachers, and male students; the mothers expressed discomfort and fear in regard to talking about menstruation with their daughters because they lacked formal MHHM education, teachers admitted 
difficulty in teaching menstruation and reproductive health because of cultural norms and disapproval from parents, and students described their teachers, particularly male teachers, as scared to teach about menstruation and only giving the class an overview of the topic. From these findings, the study recommends schools to have policies, facilities, and resources to allow girls to discreetly and affordably manage menstruation, providing comprehensive menstruation education to be provided to pre-menarche primary school girls, strengthening teachers' capacities so they can provide in-depth and accurate information in schools, and local and national governments to enact policies that encourage adequate WASH facilities in schools (73). In order to tackle MHHM issues from a comprehensive, community approach, it is essential to broaden the scope of the target population and engage a wide range of stakeholders. Treating MHHM as a human rights issue encourages programs to take such a comprehensive approach.

\section{Limitations}

Limitations exist in every study. This study included a time limit to conduct the searches, which may have led researchers to miss some articles that could have qualified for the study. There were multiple coders, which may have resulted in discrepancies of coding. However, in an attempt to eliminate these discrepancies, a thorough screening of the articles that qualified for the study was conducted by one of the co-authors and $20 \%$ of those articles were reassessed by an external reviewer to evaluate inter-rater reliability. This also ended up being a narrative systematic review rather than a meta-analysis because the study team believed it was necessary to include qualitative and mixed-methods studies. Only English publications that were available online were included in the search, reducing the generalizability to nonEnglish publications.

Publication bias could also be a concern, but this was minimized since grey-literature (reports) were allowed as part of the inclusion criteria. In terms of the location of the studies, although there were no exclusion criteria for geographical setting of the studies, all studies were from low and middle-income countries. This limited the extent of analysis for studies in developed countries.

\section{Recommendations}

$\mathrm{MHHM}$ as a construct has not been measured consistently within scientific studies. There has only been one study that conducted a psychometric testing of a MHHM scale and, even then, only in the pre-testing phase (74). Reliable and valid measures are essential to understanding the burden of inadequate MHHM within communities. Furthermore, MHHM has been studied in silos, focusing on its relationship with individual issues in WASH, health, hygiene and nutrition, education, and child protection, despite the fact that MHHM cuts across several SDG goals. There is a need to focus on MHHM as a cross-cutting topic and generating understanding that improvements in MHHM could impact multiple SDGs.

One way to elevate MHHM into the global development agenda is to push for MHHM as a human rights issue. Countries, states, and communities can: 1) provide infrastructure within schools for separate water and sanitation facilities that are gender sensitive and responsive to adolescent girls' needs; 2) incorporate 
menstruation education into school curricula to increase pre-menarche preparedness and enable open dialogues with peers, teachers, and family; 3 ) provide affordable sanitary materials to increase school attendance and retention, as well as to decrease RTI; 4) give access to adolescent-friendly reproductive services through the existing health system; and 5) provide safe and discreet disposal facilities of used menstrual products.

However, countries and states will be challenged to meet these recommendations if the current taboos around menstruation remain unchanged. Participatory methods would be an effective way to break the silence and increase communication about MHHM among community members. At the same time, states can protect and respect the rights of adolescent girls by engaging and contracting with local grassroots non-governmental organizations to educate adolescent girls, boys, mothers, fathers, and community members to decrease stigma and to increase dialogue about menstruation $(4,75)$. Participatory methods would be effective tools to empower community members as implementers and change cultural norms to make sustainable changes around MHHM.

Human rights documents need to place greater emphasis on MHHM issues; as one literature review demonstrated, menstruation is a neglected topic in such documents and is only suggested ambiguously, even though it cuts across many human rights articles and treaties (76). Until MHHM is treated as a human rights issue and explicitly acknowledge in human rights documents, it is challenge to holding states, countries, and governments accountable for addressing inadequate MHHM (76).

\section{Conclusion}

The Charter of Compassion states, "The principle of compassion lies at the heart of all religious, ethical and spiritual traditions, calling us always to treat all others as we wish to be treated ourselves" (77). Although menstruation is a normal biological process, it is associated with impurity and considered a taboo in many countries worldwide. The silence around menstruation generated by the taboo makes women and adolescent girls vulnerable to many human rights and health violations. It is essential examine MHHM as a cross-cutting, multi-disciplinary, human right issue, that is key to achieving several SDGs.

\section{Abbreviations}

MHHM- menstrual health and hygiene management

SDG- Sustainable Development Goals

WASH- water and sanitation hygiene

UDHR- Universal Declaration of Human Rights 
STI- sexually transmitted infection

\section{Declarations}

\section{Ethics approval and consent to participate}

Not applicable

\section{Consent for publication}

Not applicable

\section{Availability of data and materials}

The datasets generated during and/or analyzed during the current study are available from the corresponding author on reasonable request.

\section{Competing interests}

The authors declare that they have no competing interests.

\section{Funding}

Not applicable

\section{Authors' contributions}

SS1 was the principal investigator, oversaw the review process, and edited the manuscript. SS2 and MO reviewed the data and wrote and edited the manuscript. AR conducted the majority of the review and assisted with manuscript writing. $\mathrm{MH}$ reviewed and edited the manuscript. All authors read and approved the final manuscript.

\section{Acknowledgements}

The authors would like to thank Carmen Cronin, Jessica Lopez, Tashi Lhamo, Manasvi Shah, and Mariana Chilton for their support and assistance in conducting the review. 


\section{References}

1. Martin E, McFerran T. Menarche. In: Press OU, editor. A Dictionary of Nursing. 2014.

2. Sommer M, Sahin M. Overcoming the taboo: Advancing the global agenda for menstrual hygiene management for schoolgirls. American Journal of Public Health. 2013;103(9):1556-9.

3. WHO/UNICEF Joint Monitoring Programme. Meeting Report of the JMP Post-2015 Global Monitoring Working Group on Hygiene. Washington D.C.; 2012.

4. Hennegan J, Montgomery P. Do Menstrual Hygiene Management Interventions Improve Education and Psychosocial Outcomes for Women and Girls in Low and Middle Income Countries? A Systematic Review. PLoS One. 2016;11(2).

5. Mahon T, Fernandes M. Menstrual hygiene in South Asia: a neglected issue for WASH (water, sanitation and hygiene) programmes. Gender \& Development. 2010;18(1):99-113.

6. UNICEF. Guidance on Menstrual Health and Hygiene. New York, NY 2019.

7. UNDP. Post-2015 Sustainable Development Agenda. [Available from: http://www.undp.org/content/undp/en/home/mdgoverview/post-2015-development-agenda.html.

8. Sommer M, Sutherland C, Chandra-Mouli V. Putting menarche and girls into the global population health agenda. Reproductive Health. 2015;12(1):10-2.

9. Sumpter C, Torondel B. A Systematic Review of the Health and Social Effects of Menstrual Hygiene Management. PLoS One. 2013;8(4). 
10. UNICEF. A Communication Framework: Menstrual Management. New Delhi, India; 2015.

11. Cross D, Shaw T, Hadwen K, Cardoso P, Slee P, Roberts C, et al. Longitudinal impact of the Cyber Friendly Schools program on adolescents' cyberbullying behavior. Aggress Behav. 2016;42(2):166-80.

12. Haque SE, Rahman M, Itsuko K, Mutahara M, Sakisaka K. The effect of a school-based educational intervention on menstrual health: an intervention study among adolescent girls in Bangladesh. BMJ Open. 2014;4(7).

13. Bodat S, Ghate M, Majumdar J. School absenteeism during menstruation among rural adolescent girls in Pune. National Journal of Community Medicin. 2013;4(2):212-6.

14. Mathew K, Zachariah S, Shordt K, Snel M, Cairncross S, Biran A, et al. The sustainability and impact of school sanitation, water and hygiene education in southern India. Waterlines. 2009;28(4):275-92.

15. Shingade PP, Suryavanshi J, Kazi Y. Menstrual hygiene among married women : a hospital based cross- sectional study in an urban slum of Mumbai, India. International Journal of Community Medicine and Public Health. 2016;3(1):57-61.

16. Lakshmi Narayanamma V, Indira I, Guru Prasad G, Jyothsna J. Adolescent Menstrual Problems in a Rural Community in Andhra Pradesh. National Journal of Community Medicine. 2016;5(2).

17. Chothe V, Khubchandani J, Seabert D, Asalkar M, Rakshe S, Firke A, et al. Students' Perceptions and Doubts About Menstruation in Developing Countries: A Case Study From India. Health Promotion Practice. 2014;15(3):319-26.

18. Farage MA, Miller KW, Davis A. Cultural aspects of menstruation and menstrual hygiene in adolescents. Expert Review of Obstetrics \& Gynecolog. 2011;6(2):127-39. 
19. Goel MK, Kundan M. Psycho-Social Behaviour of Urban Indian Adolescent Girls during

menstruation. Australasian Medical Journal. 2011;4(1):49-52.

20. Guterman M, Mehta P, Gibbs M. Menstrual Taboos Among Major Religions. The Internet Journal of World Health and Societal Politics. 2008;5(2):1-6.

21. House S, Mahon T, Cavill S. Menstrual hygiene matters hygiene around the world. 2012.

22. Kumar A, Srivastava K. Cultural and Social Practices Regarding Menstruation among Adolescent Girls. Social Work in Public Health. 2011;26(6):594-604.

23. Kumar D, Goel NK, Puri S, Gupta N. Dietary Practices During Menstruation Among Unmarried Girls In Chandigarh. International Journal of Medical Science and Clinical Inventions. 2015;2(4):860-5.

24. Kumar S, Singh AK. Menstrual Practices and Hygiene among Adolescent: A Cross- sectional study in urban area of Garhwal , Uttarakhand. International Journal of Interdisciplinary and Multidisciplinary Studies. 2014;2(2):157-62.

25. Paria B, Bhattacharyya A, Das S. A comparative study on menstrual hygiene among urban and rural adolescent girls of west bengal. Journal of Family Medicine and Primary Care. 2014;3(4):413-7.

26. Ramaiya A, Malhotra A, Sood S. Individual and community level correlates for menstrual restrictions: A population based cross-sectional study in rural Uttar Pradesh, India. 2016.

27. Savanthe A, Nanjundappa V, Charles N. Menstruation: a cross-sectional study on knowledge, belief, and practices among adolescent girls of junior colleges, Kuppam, Andhra Pradesh. International Journal of Medical Science and Public Health,. 2015;5(1):1. 
28. Shanbhag D, Shilpa R, D'Souza N, Josephine P, Singh J, Goud BR. Perceptions regarding menstruation and practices during menstrual cycles among high school going adolescent girls in resource limited settings around Bangalore city, Karnataka, India. International Journal of Collaborative Research on Internal Medicine and Public Health. 2012;4(7):1353-62.

29. Tiwari H, Oza UN, Tiwari R. Knowledge, attitudes and beliefs about menarche of adolescent girls in Anand district, Gujarat. Eastern Mediterranean Health Journal. 2006;12(3-4):428-33.

30. Sen A. Development as Freedom. New York, NY: Anchor Books; 1999.

31. Field E, Ambrus A. Early Marriage, Age of Menarche, and Female Schooling Attainment in Bangladesh. Journal of Political Economy. 2008;116:881-930.

32. Ibitoye M, Choi C, Tai H, Lee G, Sommer M. Early menarche: A systematic review of its effect on sexual and reproductive health in low- and middle-income countries. PLoS One. 2017;12(6):e0178884.

33. Raj A, Ghule M, Nair S, Saggurti N, Balaiah D, Silverman JG. Age at menarche, education, and child marriage among young wives in rural Maharashtra, India. Int J Gynaecol Obstet. 2015;131(1):103-4.

34. Garg R, Shobha G, Gupta S. India moves towards menstrual hygiene: Subsidized sanitary napkins for rural adolescent girls - Issues and challenges. Maternal and Child Health Journal. 2012;16(4):767-74.

35. Garg S, Sharma N, Sahay R. Socio-cultural aspects of menstruation in an urban slum in Delhi, India. Reproductive Health Matters. 2011;9(17):16-25.

36. United Nations Human Rights. Every woman's right to water, sanitation and hygiene 2014 [Available from: https://www.ohchr.org/EN/NewsEvents/Pages/Everywomansrighttowatersanitationandhygiene.aspx]. 
37. Menstrual Hygiene Day. Menstrual Hygiene is fundamental to realizing Human Rights 2014 [Available from: http://menstrualhygieneday.org/wp-content/uploads/2014/04/HumanRights.pdf].

38. UN General Assembly. Universal declaration of human rights Geneva, Switzerland1948 [Available from: http://www.un.org/en/universal-declaration-human-rights/].

39. United Nations Human Rights. International Human Rights Law [Available from: https://www.ohchr.org/EN/Professionallnterest/Pages/InternationalLaw.aspx].

40. Sirriyeh R, Lawton R, Gardner P. Reviewing studies with diverse designs: the development and evaluation of a new tool. Journal of Evaluation in Clinical Practice. 2011;18(4):746-52.

41. Auemaneekul N, Bhandari S, Kerdmongkol P. Menstrual Hygiene Practice among Adolescent in a Rural District of Nepal. Asia Journak of Public Halth. 2013;4(December):8-15.

42. Gultie T. Practice of Menstrual Hygiene and Associated Factors among Female Mehalmeda High School Students in Amhara Regional State, Ethiopia. Science Journal of Public HEalth. 2014;2(3):18995.

43. Jones T, Smith E, Ward R, Dixon J, Hillier L, Mitchell A. School experiences of transgender and gender diverse students in Australia. Sex Education. 2015;16(2):156-71.

44. Montgomery P, Ryus CR, Dolan CS, Dopson S, Scott LM. Sanitary Pad Interventions for Girls' Education in Ghana: A Pilot Study. PLoS One. 2012;7(10):1-7.

45. Naeem K, Klawitter S, Aziz A. Learning, acting, and learning (LAL) research on schools' menstrual hygiene management (MHHM): Pakistan. Waterlines. 2015;34(1):103-12. 
46. Shah SP, Nair R, Shah PP, Modi DK, Desai SA, Desai L. Improving quality of life with new menstrual hygiene practices among adolescent tribal girls in rural Gujarat, India. Reproductive Health Matters. 2013;21(41):205-13.

47. Varghese M, Ravichandran L, Anandhan AK. Knowledge and Practice of Menstrual Hygiene among School Going Adolescent. Ind J Youth Adol Health. 2015;3(2):35-43.

48. Rizvi N, Ali TS. Misconceptions and Mismanagement of Menstruation among Adolescents Girls who do not attend School in Pakistan. Journal of Asian Midwives. 2016;3(1).

49. Kusuma ML, Ahmed M. Awareness, perception and practices of government pre-university adolescent girls regarding menstruation in Mysore city , India. International Journal of Community Medicine and Public Health Kusuma. 2016;3(6):1593-9.

50. Fakhri M, Hamzehgardeshi Z, Hajikhani Golchin NA, Komili A. Promoting menstrual health among persian adolescent girls from low socioeconomic backgrounds: a quasi-experimental study. BMC Public Health. 2012;12(1):193.

51. Anand E, Singh J, Unisa S. Menstrual hygiene practices and its association with reproductive tract infections and abnormal vaginal discharge among women in India. Sexual \& Reproductive Healthcare. 2015;6(4):249-54.

52. Balamurugan S, Shilpa S, Shaji S. A community based study on menstrual hygiene among reproductive age group women in a rural area, Tamil Nadu. Journal of Basic and Clinical Reproductive Sciences. 2014;3(2):83.

53. Bathija GV, Bant DD, Itagimath SR. Study on usage of woman hygiene kit among menstruating age group in field practice area of KIMS, Hubli. International Journal of Biomedical Research. 2013;4(2):94-8. 
54. Khanna A, Goyal RS, Bhawsar R. Menstrual Practices and Reproductive Problems: A Study of Adolescent Girls in Rajasthan. Journal of Health Management. 2005;7(1):91-107.

55. Sumana Y, Damor R, Kantharia SL. Menstrual Hygiene: Gaps in the Knowledge and Practices in Adolescent School Girls. Journal of Evidence Based Medicine and Healthcare. 2015;2(17):2487-92.

56. Walraven G, Ekpo G, Coleman R, Scherf C, Morison L, Harlow SD. Menstrual disorders in rural Gambia. Studies in Family Planning. 2002;33(3):261-8.

57. Dongre A, Deshmukh P, Garg B. The effect of community-based health education intervention on management of menstrual hygiene among rural Indian adolescent girls. World Health \& Population. 2007;9(3):48-54.

58. Santina T, Wehbe N, Ziade FM, Nehme M. Assessment of Beliefs and Practices Relating to Menstrual Hygiene of Adolescent Girls in Lebanon. International Journal of Health Sciences and Research. 2013;3(12):75-88.

59. Aniebue UU, Aniebue PN, Nwankwo TO. The impact of pre-menarcheal training on menstrual practices and hygiene of Nigerian school girls. The Pan African Medical Journal. 2009;2(9).

60. Arora A, Mittal A, Pathania D, Singh J, Mehta C, Bunger R. Impact of health education on knowledge and practices about menstruation among adolescent school girls of rural part of district Ambala, Haryana. Indian Journal of Community Health. 2013;25(4):492-7.

61. Chiou M-H, Wang H-H, Yang Y-H. Effect of Systematic Menstrual Health Education on Dysmenorrheic Female Adolescents' Knowledge, Attitudes, and Self-Care Behavior. The Kaohsiung Journal of Medical Sciences. 2007;23(4):183-90.

62. Chiou M-H, Wang H-H. Predictors of Dysmenorrhea and Self-Care Behavior Among Vocational Nursing School Female Students. Journal of Nursing Research. 2008;16(1):17-25. 
63. Djalalinia S, Tehrani FR, Afzali HM, Hejazi F, Peykari N. Parents or school health trainers, which of them is appropriate for menstrual health education? International Journal of Preventive Medicine. 2012;3(9):622-7.

64. Ekong IE. Health Seeking Behaviour for Menstrual Problems Among School Girls and its Associated Factors: An implication for Health Education. International Journal of Current Research. 2015;7(8):19638-44.

65. El-Lassy RB, Madian AAE-A. Impact of Health Educational Program on Menstrual Beliefs and Practices of Adolescent Egyptian Girls at Secondary Technical Nursing School. Life Science Journal. 2013;10(2):335-45.

66. Fetohy EM. Impact of a health education program for secondary school Saudi girls about menstruation at Riyadh city. The Journal of the Egyptian Public Health Association. 2007;82(1-2):10526.

67. Nemade D, Anjenaya S, Gujar R. Impact of health education on knowledge and practices about menstruation among adolescent school girls of Kalamboli, Navi-mumbai. Health and Population: Perspectives and Issues. 2009;32(4):167-75.

68. Pokhrel S, Mahantashetti N, Angolkar M, Devkota N. Impact of Health Education on the Knowledge and Practice Regarding Personal Hygiene among Pre University Female Students of a College Located in Urban Area of Belgaum. IOSR Journal of Nursing and Health Science. 2014;3(4):38-44.

69. Vijaysree L, GN K, Vaz Sequeira L, Rao SR. A Study on Menstrual Practices and Hygiene Among Adolescent Girls in a Government High School. Indian Journal of Medical Research and Pharmaceutical Sciences. 2016;3:55-60. 
70. UNICEF, World Health Organization. Joint Monitoring Programme for Water Supply, Sanitation and Hygiene. 2016.

71. Tamiru S, Mamo K, Acidria P, Mushi R, Ali CS, Ndebele L. Towards a sustainable solution for school menstrual hygiene management: Tanzania, and Zimbabwe. Waterlines. 2015;34(1):92-102.

72. Sommer M, Caruso BA, Sahin M, Calderon T, Cavill S, Mahon T, et al. A Time for Global Action: Addressing Girls' Menstrual Hygiene Management Needs in Schools. PLoS Medicine. 2016;13(2).

73. Long J, Caruso BA, Lopez D, Vancraeynest K, Sahin M, Andes KL, et al. WASH in Schools Empowers Girls' Education in Rural Cochabamba, Bolivia.; 2014.

74. Ray S, Aparajita D. Determinants of Menstrual Hygiene among Adolescent Girls: A Multivariate Analysis. National Journal of Community Medicine. 2012;3(2):294-301.

75. Neumeyer H. Menstrual Hygiene \& Human Rights: A bloody road to a more equal world.

76. Boosey R, Wilson E. The Menstrual Hygiene Management and The International Human Rights System: A Vicious Cycle of Silence. 2014.

77. Charter of Compassion. Charter of Compassion 2015 [Available from: https://www.charterforcompassion.org/index.php/charter/charter-overvew.

\section{Figures}




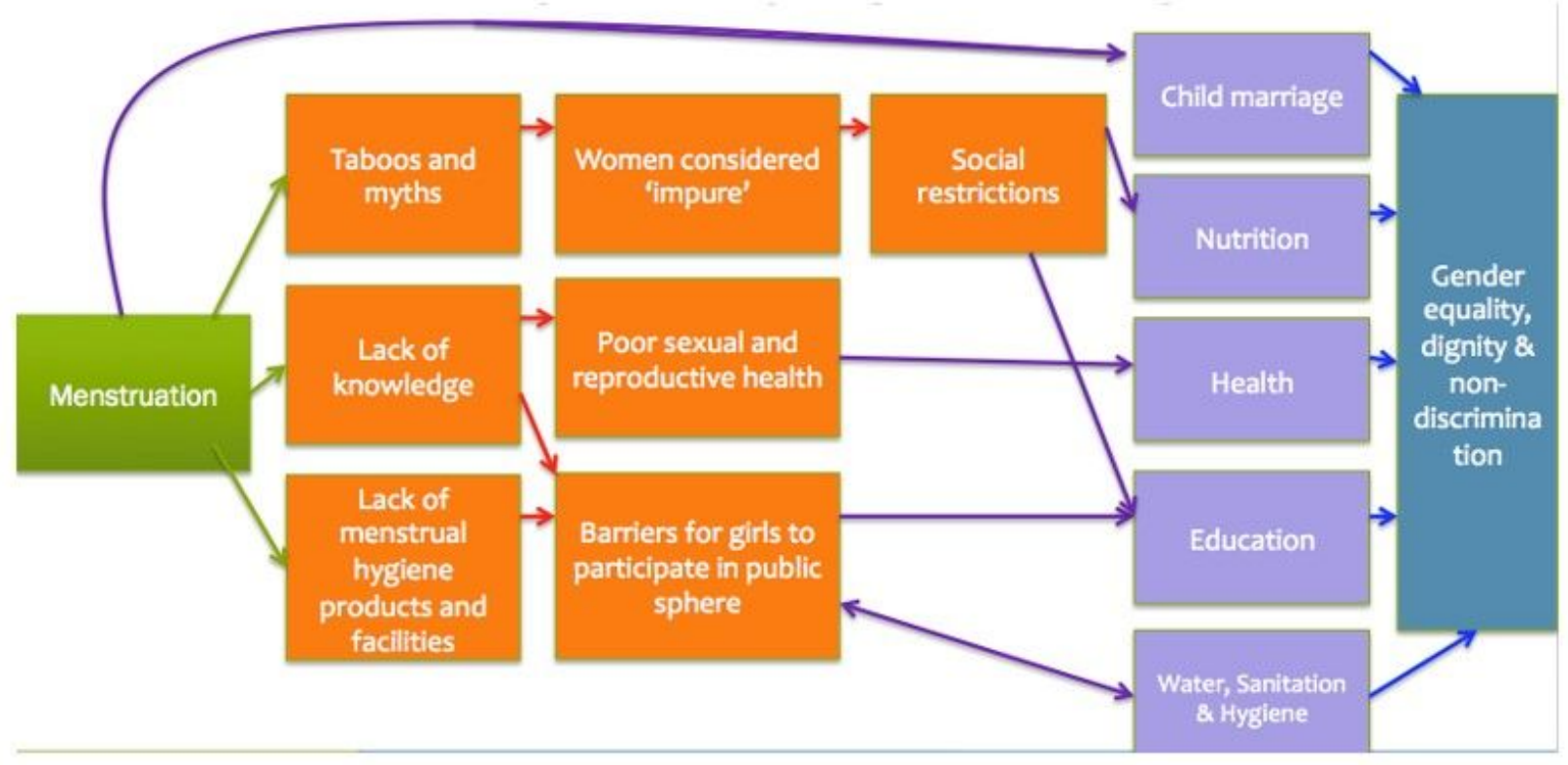

\section{Figure 1}

Health and Human Rights Framework adapted from Neumeyer (Neumeyer, n.d.) 


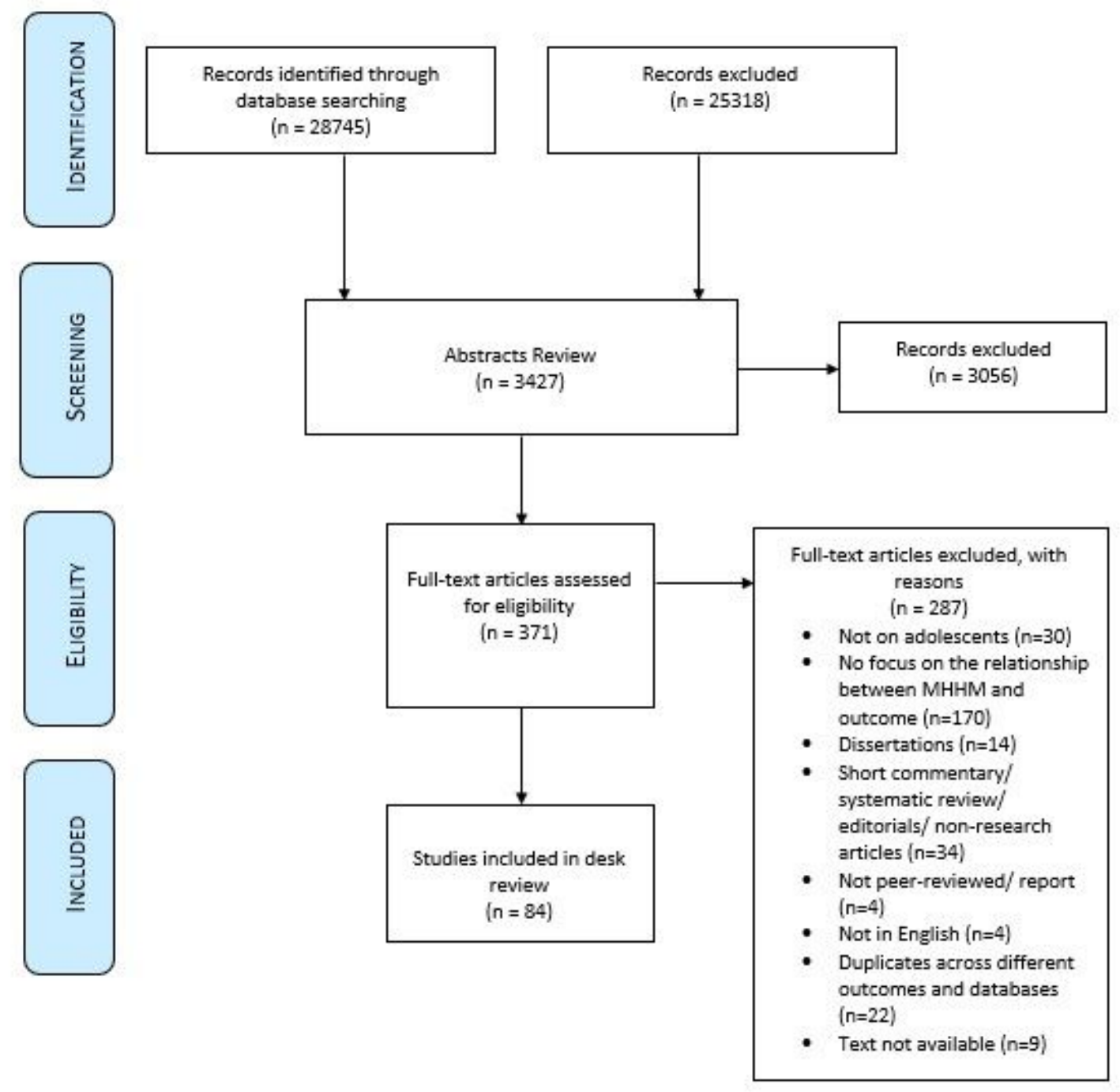

Figure 2

Systematic outline of the review process 